\title{
Személyre szabott kezelés szinkrón, nyirokcsomó-pozitív petefészek- és vastagbéldaganatban
}

\author{
Deme Dániel dr. ${ }^{1}$. Abdulfatah M. Bishr dr. ${ }^{1}$ \\ Jamool Nizar dr. ${ }^{2}$. Telekes András dr. ${ }^{1,3}$ \\ Szent Lázár Megyei Kórház, 'Onkológia, ${ }^{2}$ Patológia, Salgótarján \\ ${ }^{3}$ Bajcsy-Zsilinszky Kórház, Onkológia, Budapest
}

\begin{abstract}
A 71 éves nőbetegnél jobb alhasi fájdalom és láz miatt sürgősségi laparotomiára került sor. Makroszkóposan duplex coecum és colon transversum, továbbá szigma/bal petefészek daganatának gyanúja merült fel. A szövettani vizsgálat szinkrón bal petefészek- (papillaris adenocarcinoma) és colon transversum (tubularis adenocarcinoma) daganatot mutatott. Mind a két primer daganat a regionális nyirokcsomóikba adott áttétet, továbbá a petefészek-daganat infiltrálta a szigmabelet és távoli áttétet képzett a coecum területére. Immunhisztokémiával a nyirokcsomóáttétek egyértelmúen elkülöníthetők voltak: petefészek-eredetű CK7-pozitív, coloneredetű CK20- és CEA-pozitív. A szikrón primer daganatokat kombinált kemoterápiával kezeltük (FOLFOX-4 és heti paclitaxel). A kombinált kezelést a beteg jól tolerálta. A ritka eset hangsúlyozza annak jelentőségét, hogy a többszörös primer daganatok egyénre szabott kemoterápiás sémával kezelhetők jó hatásfokkal és enyhe mellékhatásokkal. Orv. Hetil., 2015, 156(23), 939-943.
\end{abstract}

Kulcsszavak: szinkrón petefészek-daganat, vastagbéldaganat, nyirokcsomó-pozitivitás, kombinált kemoterápia

\section{Individualized therapy of synchronous ovarian and colon cancers with lymph node positivity. Case report}

\begin{abstract}
A 71-year-old female patient underwent urgent laparotomy due to severe right lower quadrant abdominal pain and fever. Macroscopically duplex coecal and transverse colon cancer as well as a sigmoid or left ovarian cancer were suspected. Pathological findings revealed synchronous left ovarian and transverse colonic neoplasms. Both primaries metastatized to their regional lymph nodes. Furthermore, the ovarian cancer infiltrating the sigmoid colon gave distant metastasis in the coecum, too. Ovarian cancer histology showed papillary adenocarcinoma, and transverse colon cancer was a tubular adenocarcinoma. The affected lymph nodes were clearly distinguished by immunohistochemistry staining: ovarian metastases were CK7 positive, and colonic metastases were CK20 and CEA positive. The patient was treated with combinated chemotherapy: FOLFOX-4 two weekly and paclitaxel monotherapy every other week. The patient tolerated this combined treatment well. The authors conclude that multiple synchronous neoplasms can be treated with individualized chemotherapeutic protocol with good efficacy and few adverse reactions.
\end{abstract}

Keywords: synchronous ovarian cancer, colon cancer, lymph node positivity, combined chemotherapy

Deme, D., Bishr, A. M., Nizar, J., Telekes, A. [Individualized therapy of synchronous ovarian and colon cancers with lymph node positivity. Case report]. Orv. Hetil., 2015, 156(23), 939-943.

(Beérkezett: 2015. március 17.; elfogadva: 2015. április 16.) 


\section{Rövidítések}

$5 \mathrm{FU}=5$-fluorouracil; $\mathrm{CRC}=$ colorectalis carcinoma; $\mathrm{CRR}=$ teljes válaszarány; FOLFOX $=$ calcium folinate +5 -fluorouracil + oxaliplatin; ORR = összes válaszarány; OS = teljes túlélés; $\mathrm{PFS}=$ progressziómentes túlélés; $\mathrm{PRR}=$ részleges válaszarány; RFS = kiújulásmentes túlélés; $\mathrm{SD}=$ stabil betegség; TTP = progresszióig eltelt idő

Retrospektív analízis alapján a nőgyógyászati daganatok diagnózisának idópontjában szinkrón második primer daganat is jelen van (például: emlő, gyomor, vastagbél, pajzsmirigy). A szinkrón daganatok aránya megközelítőleg $1,4 \%(\mathrm{n}=1044)$. A petefészek-daganatos betegek 9,8\%-ában $(\mathrm{n}=123)$ többszörös primer daganat van jelen, és a leggyakrabban érintett szerv az emlő [1].

Oxaliplatin és 5-fluorouracil kombináció javította a túlélést mucinosus petefészek-daganatos xenograftmodellen [2]. Retrospektív fázis 2 vizsgálat szerint a FOLFOX-4 hatékony terápiás választás a platinarezisztens (platinatartalmú kemoterápia után $\mathrm{PFS}<6$ hónap) és taxánnal előkezelt áttétes petefészekrákban $(\mathrm{n}=38)$. A CRR, PRR, ORR és SD 7,9\%, 21,1\%, 29\% és 29\% sorrendben. A medián RFS, TTP és OS 5,2, 4,8 és 10,1 hónap sorrendben. Toxicitás enyhétől a mérsékelt súlyossági fokig terjedt [3]. Egy fázis 2 vizsgálat igazolta a hatékonyságát a 3 hetente adott paclitaxel $\left(175 \mathrm{mg} / \mathrm{m}^{2}\right)$ és oxaliplatin $\left(130 \mathrm{mg} / \mathrm{m}^{2}\right)$ kombinációnak olyan páciensek esetén, akik platinaérzékenyek (PFS>6 hónap, megelőző cisplatin- és/vagy carboplatinalapú kemoterápia után) $(\mathrm{n}=98)$. ORR $81 \%$ volt. Medián PFS, OS 10,2 és 32,4 hónap volt sorrendben [4]. Egy fázis 2 vizsgálat (NCT 01481701) a FOLFOX-4 hatékonyságát méri fel rekurráló petefészek-daganatban. Másik randomizált fázis 3 vizsgálat (NCT 01081262) összehasonlítja a hatékonyságát a paclitaxel+carboplatin \pm bevacizumab és oxali platin+capecitabine \pm bevacizumab karoknak II-IV. stádiumú újonnan diagnosztizált vagy rekurráló epithelialis petefészek- vagy tuba-Fallopii-daganatokban.

Carboplatin-monoterápiában nem mutatott daganatellenes hatást sem előrehaladott, 5 FU-előkezelt $(\mathrm{n}=21)$ [5], sem áttétes vastagbéldaganatban $(\mathrm{n}=56)$ [6]. Azonban egy francia tanulmány $(\mathrm{n}=76) 60 \%$-os major daganatválaszt mutatott áttétes CRC-ben első vonalbeli carboplatin és 5FU kombinációs kezelést követően. Major válaszarány $68 \%$ volt azon páciensek esetén, akik nem kaptak adjuváns kemoterápiát [7].

\section{Esetismertetés}

71 éves nőbetegünk kórelőzményében anxietas miatti pszichiátriai kezelés, cholecystectomia, hypertonia és lumbalis spondylosis szerepel. Lánytestvérének vékonybéldaganata volt. A beteg 4 hónap alatt $11 \mathrm{~kg}$-ot fogyott. Súlyos jobb alhasi fájdalom és láz miatt sürgős laparotomiára került sor. Makroszkóposan szimultán coecum-, colon transversum és szigma- vagy bal oldali petefészek- daganat gyanúja merült fel. Hemicolectomia dextra, colon transversum és szigmareszekció és bal oldali adnexectomia történtek. Differenciáldiagnosztikailag felmerült malignus carcinoid vagy petefészek-daganat is. A szövettani vizsgálat szinkrón colon transversum és bal petefészek-daganatot mutatott. A két primer áttétet képzett a regionális nyirokcsomóikba. Továbbá a szigmabelet infiltráló ovariumdaganat áttétet adott a coecum területére $(10 \mathrm{~cm}$ átmérőjü, submucosa területén terjedő és serosába hatoló) és annak regionális nyirokcsomóiba. A metasztatikus petefészek-daganat szövettana: adenocarcinoma papillare, a v. mesenterica inferior területi nyirokcsomó-pozitivitással (FIGO IV $\left./ b, \mathrm{pT}_{3} \mathrm{pN}_{1} \mathrm{M}_{1}\right)$. A colon transversum szövettana: adenocarcinoma tubulare $\left(\mathrm{pT}_{3} \mathrm{pN}_{2} \mathrm{M}_{0}\right)$. Immunhisztokémiával az érintett nyirokcsomók nyilvánvalóan megkülönböztethetók voltak: petefészek-eredetü CK7-pozitív ( $1 / a$ és $1 / c$ ábra), coloneredetü CK20- és CEA-pozitív ( $1 / b$ ábra). Időnyerés céljából, mialatt a differenciáldiagnosztikai vizsgálatok zajlottak, a colondaganatra kéthetente FOLFOX-4 (140 mg oxaliplatin, calcium folinate $340 \mathrm{mg}, 5$-fluorouracil, $680 \mathrm{mg}$ bolus és $2000 \mathrm{mg} 44$ órás infúzió) kezelést kezdtünk. 3 ciklus FOLFOX-4 kezelés után - amint a petefészek-daganat diagnózisa megerôsítést nyert - hat ciklus paclitaxel-monoterápiát $(300 \mathrm{mg})$ adtunk minden második héten a FOLFOX-4 terápiás szünetében. Páciensünk a kezelést jól tolerálta. Az abszolút neutrofil-, a vörösvértestszám és a vérlemezkenadír 1,09 G/L, 4,00 $\mathrm{T} / \mathrm{L}$ és $203 \mathrm{G} / \mathrm{L}$ volt sorrendben (2. ábra). Az utolsó előtti kezelés után észleltük a vesefunkció mérsékelt beszúkülését, amely az utánkövetés során kisfokú javulást mutatott (3. ábra). A páciens nem szorult granulocytakolónia-stimulátor adására. A kombinációs kezelés után 2 ciklus FOLFOX-4 kezelést kapott. Az utolsó kemoterápia oxaliplatin infúziója alatt nehézlégzés jelentkezett. Szteroid hatására panaszai megszúntek. Légzésfunkció rendezett volt. Mellkasi CT negatív eredményt hozott. A reakciót valószínúleg az oxaliplatin allergizáló hatása okozta, emiatt a kemoterápiás kezelést abbahagytuk. A kemoterápiát követően készült képalkotó (CT, szívultrahang) és laborvizsgálatok kóros eltérést nem mutattak. A kontrollvizsgálatokon sem lokális recidíva, sem szervi áttét nem mutatkozott. A diagnózistól számított 20. hónapban páciensünket végelgyengülés következtében vesztettük el.

\section{Megbeszélés}

Ritka esetünk hangsúlyozza annak jelentőségét, hogy többszörös szinkrón daganattal rendelkező idős páciensek egyénre szabott kemoterápiával kezelhetők, amely mérsékelt mellékhatások mellett jó hatékonyságot mutat. Elérhető a daganatos betegeknél a nem daganatos egyénekével azonos élettartam, jó életminőséggel. Legjobb tudásunk szerint ez az első esetismertetés az immunhisztokémiailag igazolt szinkrón petefészek- és vastagbéldaganatról, amelyek a regionális nyirokcsomóikba 

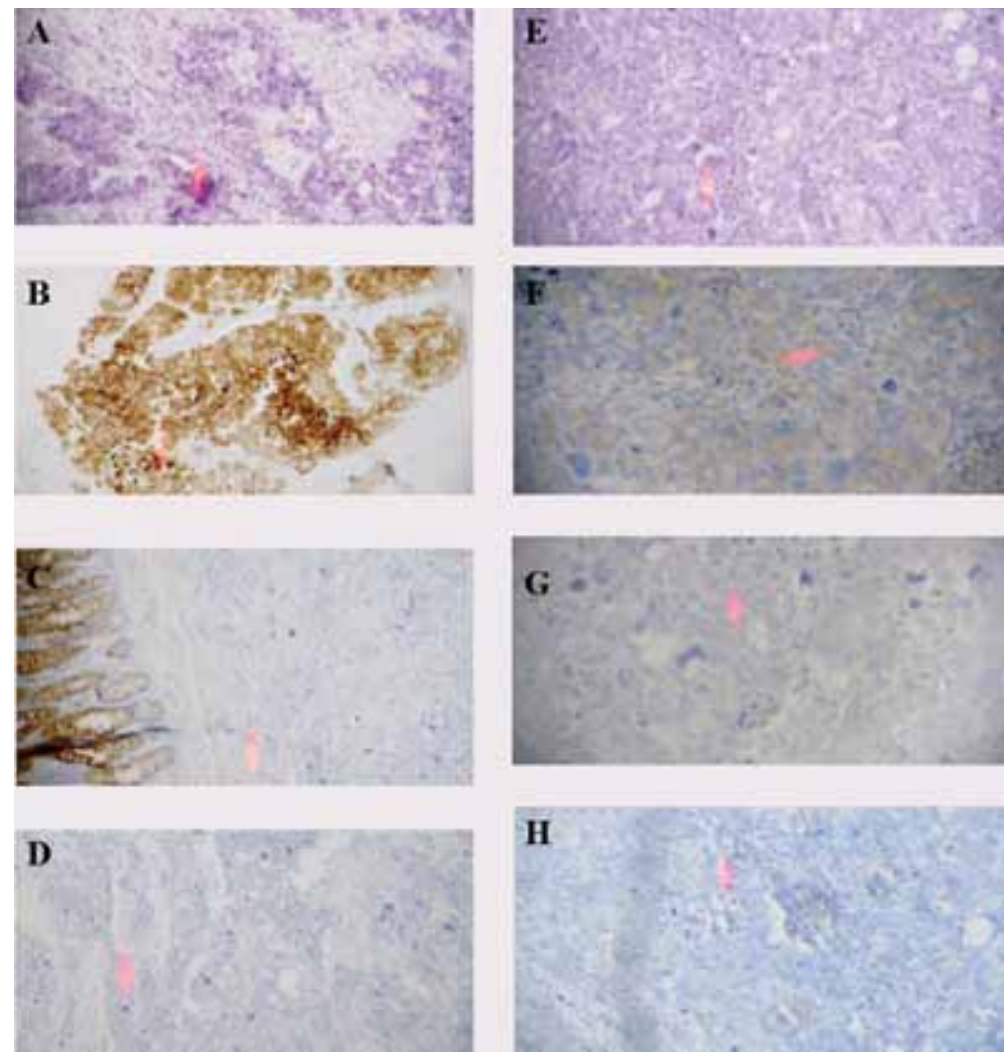

Petefészek-daganat (A-D) és a regionális nyirokcsomó áttétjei $(\mathrm{E}-\mathrm{H})$

A: hematoxilin-eozin; B: CK7-pozitivitás; C: CK20-negativitás és pozitív belső kontroll; D: CEA-negativitás; E: hematoxilin-eozin; F: CK7-pozitivitás; G: CK20-negativitás; H: CEA-negativitás
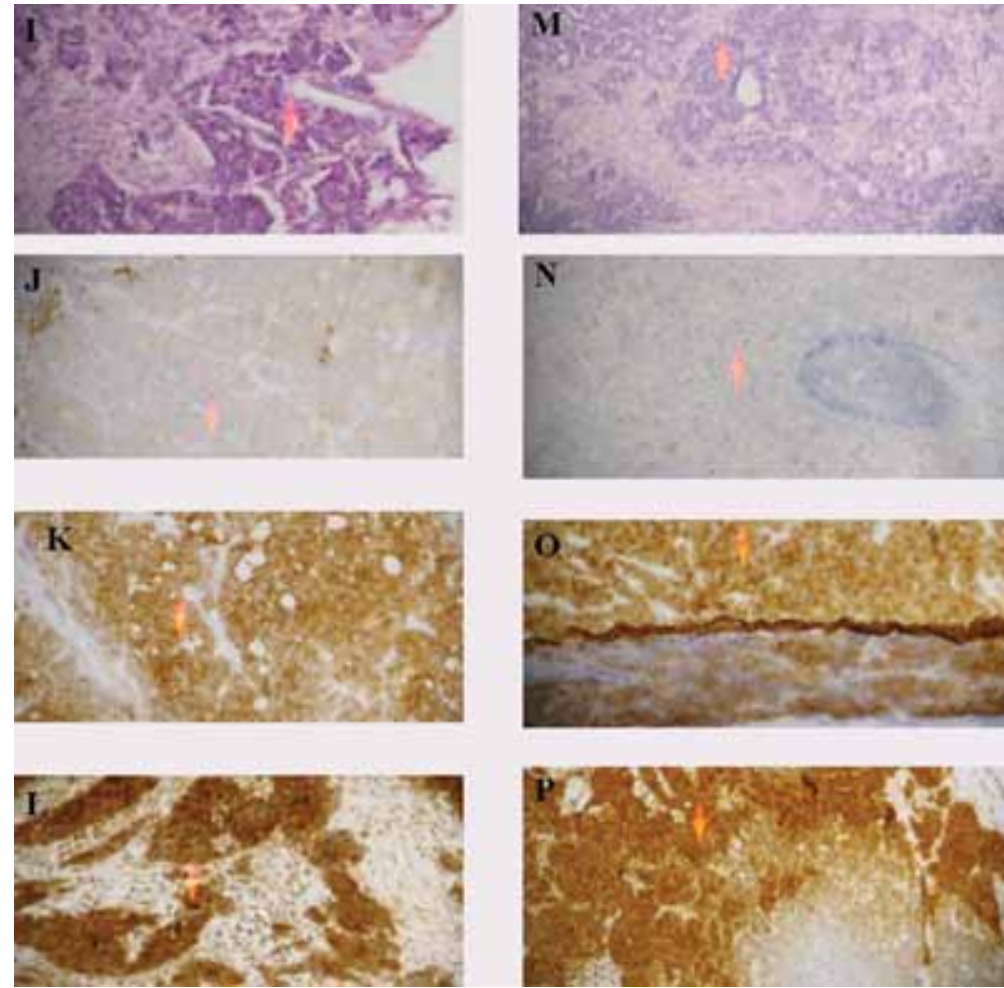

1/b ábra

A vastagbéldaganat szövettani (I-L) és a regionális nyirokcsomó áttétjei $(\mathrm{M}-\mathrm{P})$

I: hematoxilin-eozin; J: CK7-negativitás, háttérreakció; K: CK20-pozitivitás; L: CEA-pozitivitás; M: hematoxilin eozin; N: CK7-negativitás, háttérreakció; O: CK20-pozitivitás; P: CEA-pozitivitás és negatív belső kontroll 

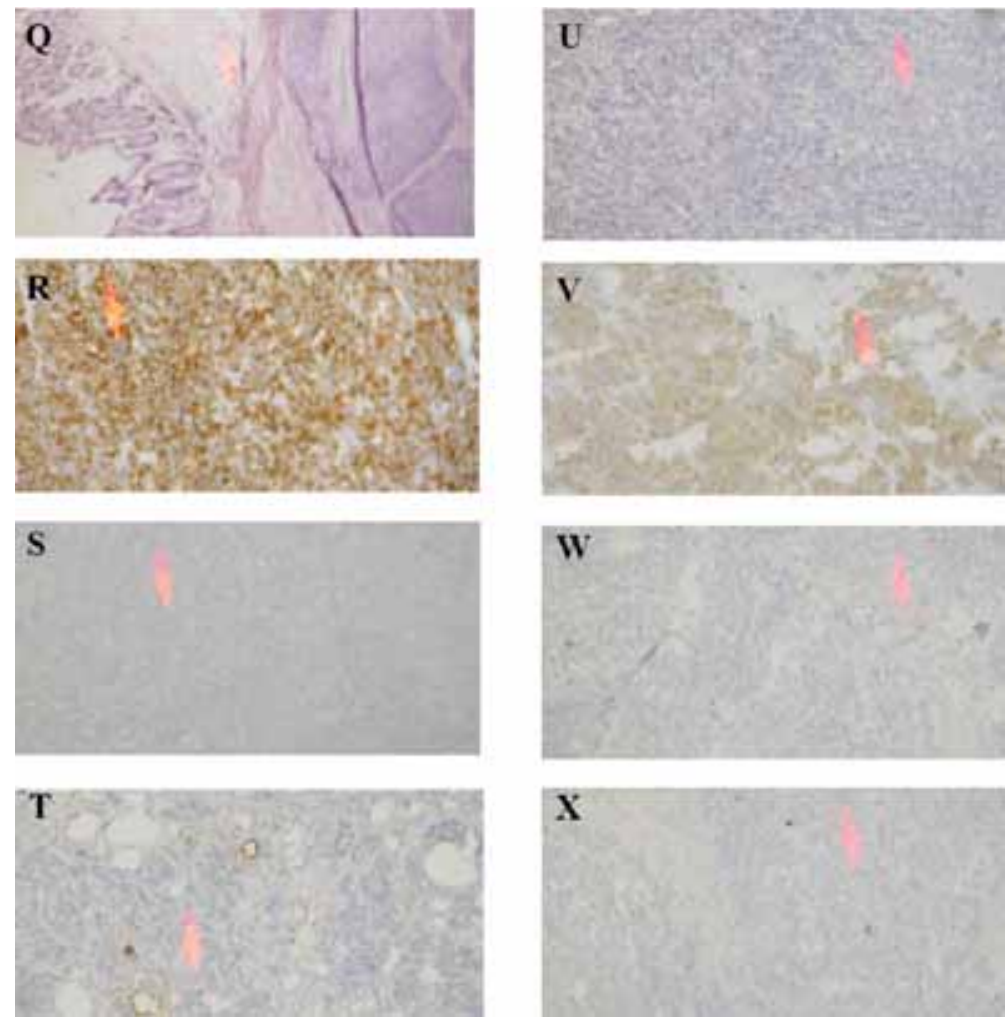

1/c ábra $\quad$ A bal petefészek-daganat coecum- $(\mathrm{Q}-\mathrm{T})$ és a regionális nyirokcsomó áttétjei (U-X)

Q: hematoxilin-eozin és submucosalis infiltráció; R: CK7-pozitivitás; S: CK20-negativitás; T: CEA-negativitás; U: hematoxilin-eozin; V: CK7-pozitivitás; W: CK20-negativitás; X: CEA-negativitás

man........ abs. Neu (G/L)

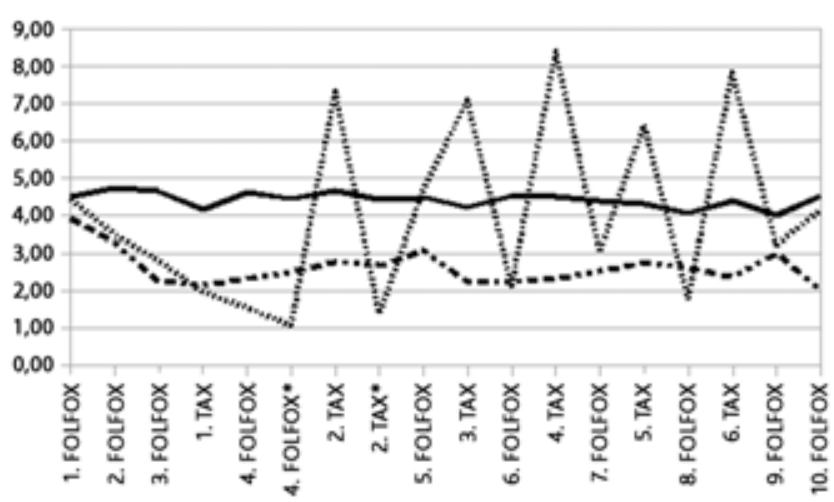

2. ábra A vérkép relatív értékeinek változása a kezelés alatt
A mintákat a kezelések előtt vettük le. A jelzett (*) értékek a
kezelést követően kerültek mérésre.
$\left({ }^{* *}\right)$ Vérlemezkeszám 100 -szorosa, mint a relatív érték.
abs. Neu = abszolút neutrofilszám; RBC = vörösvértestszám,
PLT = vérlemezkeszám

adtak áttétet. A szinkrón daganatos betegeknek a primer malignomák kezeléséhez szükséges kemoterápia, illeszkedve, teljes dózisban is megadható szoros ellenőrzés mellett.

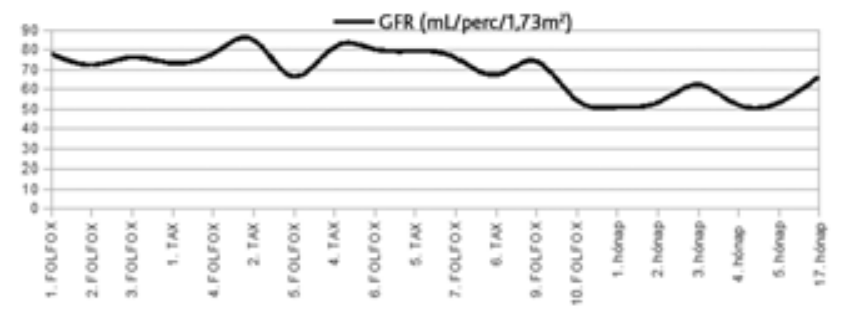

3. ábra

A vesefunkció (glomeruláris filtrációs ráta - GFR) változásai a kezelések előtt és az utánkövetés során

Anyagi támogatás: A közlemény megírása anyagi támogatásban nem részesült.

Szerzői munkamegosztás: D. D.: Irodalmi áttekintés, a dolgozat szövegének és ábráinak megszerkesztése. B. A. M.: A páciens kezelése, kórtörténetének összefoglalása. N. J.: Patológiai vizsgálatok elvégzése, szövettani felvételek készítése. T. A.: A kombinált kemoterápiás kezelésről szóló döntés meghozatala az oncoteam keretén belül. $\mathrm{Az}$ elkészült kézirat áttekintése, javaslatok megadása. A cikk végleges változatát a szerző́k elolvasták és jóváhagyták.

Érdekeltségek: A szerzőknek nincsenek érdekeltségeik. 


\section{Irodalom}

[1] Takeda, T., Sagae, S., Koizumi, M., et al.: Multiple primary malignancies in patients with gynecologic cancer. Int. J. Gynecol. Cancer, 1995, 5(1), 34-39.

[2] Sato, S., Itamochi, H., Kigawa, J., et al.: Combination chemotherapy of oxaliplatin and 5-fluorouracil may be an effective regimen for mucinous adenocarcinoma of the ovary: a potential treatment strategy. Cancer Sci., 2009, 100(3), 546-551.

[3] Pectasides, D., Pectasides, M., Farmakis, D., et al.: Oxaliplatin plus high-dose leucovorin and 5-fluorouracil (FOLFOX 4) in platinum-resistant and taxane-pretreated ovarian cancer: a phase II study. Gynecol. Oncol., 2004, 95(1), 165-172.

[4] Viens, P., Petit, T., Yovine, A., et al.: A phase II study of a paclitaxel and oxaliplatin combination in platinum-sensitive recurrent advanced ovarian cancer patients. Ann. Oncol., 2006, 17(3), $429-436$.
[5] Nolè, F., Biganzoli, L., Buzzoni, R., et al.: Carboplatin in patients with advanced colorectal cancer pretreated with fluoropyrimidines. Eur. J. Cancer, 1993, 29A(9), 1330-1331.

[6] Asbury, R. F., Kramer, A., Green, M., et al.: A phase II study of carboplatin and CHIP in patients with metastatic colon carcinoma. Am. J. Clin. Oncol., 1989, 12(5), 416-419.

[7] Focan, C., Kreutz, F., Longrée, L., et al.: Chronotherapy combining 5-fluorouracil, folinic acid and carboplatin as first line treatment in metastatic colorectal cancer. A phase 2 study. Pathol. Biol. (Paris), 2005, 53(5), 273-276.

(Deme Dániel dr., Salgótarján, Füleki út 54-56., 3100 e-mail: danieldeme_md@ymail.com)

\section{A rendezvények és kongresszusok híranyagának leadása}

a lap megjelenése elött legalább 40 nappal lehetséges, a 6 hetes nyomdai átfutás miatt. Kérjük megrendelőink szíves megértését.

A híranyagokat a következő címre kérjük: Orvosi Hetilap titkársága: Budai.Edit@akkrt.hu Akadémiai Kiadó Zrt. 